\title{
Surface mass loss characteristics of carbonized phenolic CFRP in nitrogen gas atmosphere
}

\author{
Keiichi Okuyama*,*** and Masaru Zako**
}

\begin{abstract}
When the phenolic CFRP is heated in a nitrogen gas atmosphere, the phenolic resin is pyrolyzed and the gas containing oxygen is generated. This generated oxygen oxidized the phenolic CFRP. The oxidation of carbonized phenolic CFRP in the nitrogen gas atmosphere was found to be divided into the rate-controlled oxidation region and the diffusion-controlled oxidation region. The boundary temperature was approximately $1600 \mathrm{~K}$. The activation-energy $E$, collision-frequency coefficient $k_{0}$, and diffusion-controlled oxidation constant $C_{0}$ were determined. They were used for estimating the surface mass loss rate of the carbonized phenolic CFRP in the rate-controlled oxidation region and the diffusion-controlled oxidation region. The activation energy $E$ was estimated to be $182.4 \mathrm{~kJ} / \mathrm{mol}$, and the $k_{0}$ was expressed as $k_{0}=10.0 /(\tau \mathrm{Pe})^{0.5}$, where $P_{e}$ is the stagnation pressure measured at the specimen surface. $C_{0}$ could be expressed as a function of the reaction rate $\tau$ by $C_{0}=1.3 \times 10^{-5} \ln (\tau)+3.3 \times 10^{-5}$.
\end{abstract}

KEYWORDS : CFRP, Carbonize, Phenolic resin, Recession, Rate-controlled oxidation and Diffusion-controlled oxidation

\section{Introduction}

Titan, one of the satellites of Saturn, is surrounded by an inert atmosphere chiefly composed of $80 \%$ nitrogen gas and $15 \%$ argon gas. It also contains water and hydrogen cyanide, both of which are essential for the creation of life. The atmospheric pressure near Titan's surface is $0.15 \mathrm{MPa}$. In order to thoroughly explore Titan, it is necessary to send a space vehicle down through its atmosphere. Furthermore, at the time of entry, the space vehicle is expected to experience severe aerodynamic heating. In order to prevent heat from permeating in the vehicle, the surface of the vehicle is covered with an ablator made of carbonized phenolic Carbon Fiber Reinforced Plastic (CFRP). Carbonized phenolic CFRP is known to possess high specific strength and stiffness. It is highly heat resistant and also resists the shearing load imposed by the high-speed airflow. On account of these properties, the carbonized phenolic CFRP has been widely adopted in earth re-entry vehicles, planetary exploration probes, etc. ${ }^{1)}{ }^{-6)}$.

When the airflow consists of inert gases such as nitrogen and argon, oxygen is absent from the boundary layer. Therefore, the mole fraction of oxygen in the boundary layer is set at zero.

Metzger et al. ${ }^{7)}$ clarified the surface mass loss characteristics of graphite in air. According to their study, the surface mass loss of the graphite occurs in three regions. The first is the rate-controlled oxidation region in a temperature range below $1500 \mathrm{~K}$, where the surface material dissipates, mainly as a result of its oxidation by air in the boundary layer. The second is the diffusion-controlled oxidation region in a temperature range above $1500 \mathrm{~K}$. Park ${ }^{8)}$ demonstrated that the surface mass loss of the graphite in both these regions advances chiefly according to the reaction $\mathrm{C}+\mathrm{O} \rightarrow \mathrm{CO}$. The third is the sublimation region in a temperature range above $3000 \mathrm{~K}^{7)}$, where the surface mass loss of graphite occurs predominantly through the sublimation of carbon : $3 \mathrm{C}($ Solid $) \rightarrow \mathrm{C}_{3}(\mathrm{Gas})^{8)}$.

On the other hand, based on the surface mass loss characteristics of the graphite, Potts ${ }^{9)}{ }^{10)}$ studied the surface mass loss characteristics of carbonized phenolic CFRP in air.

In order to study the surface mass loss characteristics of carbonized phenolic CFRP, Sutton ${ }^{11)}$ conducted heat experiments in atmosphere where the oxygen mole fraction varied from $23 \%$ to $0 \%$ (when the nitrogen mole fraction was approximately $100 \%)$. He observed that when the heating time ranged from $3.6 \mathrm{~s}$ to $30 \mathrm{~s}$ in nitrogen atmosphere, the carbonized phenolic CFRP exhibited an almost zero surface mass loss. When the temperature was raised to about $3000 \mathrm{~K}$, recession began by sublimation. Sutton, therefore, assumed that the surface mass loss rates in both the rate-controlled oxidation region $\dot{m}_{R}$ and the diffusion-controlled 
oxidation region $\dot{m}_{D}$ could be set at zero.

When the gas resulting from the decomposition of phenolic resin contains oxygen, carbonized phenolic CFRP is presumably oxidized by the oxygen diffusing into the boundary layer. As this assumption has not been verified, it is important to determine whether the carbonized phenolic CFRP placed in a nitrogen atmosphere experiences oxidation that results in its own recession. Because, the Metzger's theory cannot estimate the surface mass loss rate by the oxidization based on the oxygen in the pyrolysis gas diffused into the nitrogen atmosphere.

This paper describes an experimental study conducted on the surface mass loss characteristics of the carbonized phenolic CFRP, which permits space vehicles to enter into the nitrogen atmosphere.

\section{Experimental}

\subsection{Test equipments}

Heating test was performed using the arc-heating equipment owned by the Japan Ultra High Temperature Material Center (JUTEM) 12), 13) (Fig.1).

The arc-heating equipment consists of an arc heater for heating a working gas such as air or inert gases, a gas supply unit that accelerates the high enthalpy gas; a nozzle and a specimen drive unit, and an exhaust cooler. The pressure of high enthalpy airflow was measured using a Pitot tube, which stems the airflow and measures the stagnation pressure.

The surface temperatures in the conditions $\mathrm{A}$ and $\mathrm{E}$ were measured using an infrared thermometer (pyrometer), which is a sensor that detects the infrared radiation from the surface of a material.

\subsection{Test conditions and specimens}

Since the surface mass loss of the carbonized phenolic CFRP presumably depends on the surface temperature and the stagnation pressure, test pieces were subjected to surface mass loss measurements at various surface temperatures and stagnation pressures. The experimental conditions $\mathrm{A}$ through $\mathrm{C}$ were used for testing the carbonized phenolic CFRP as listed in Table 1. The purity of the nitrogen gas used for the tests of the conditions A through $\mathrm{E}$ was $99.99 \%$. Existence of gases such as oxygen and argon etc. can be ignored.

The virgin phenolic CFRP used for test the condition A had a density of approximately $1470 \mathrm{~kg} / \mathrm{m}^{3}$, and contained $20 \mathrm{wt} \%$ phenolic resin. Test pieces were made by compressing the prepreg pieces at a high temperature. In the conditions $\mathrm{B}$ and $\mathrm{C}$, the heating test was performed with the test pieces that had undergone the heating test in the condition A. The condition B was not sufficient for achieving complete thermal decomposition of the phenolic resin left in the test pieces that had undergone the heating test in the condition A.

Finally, the condition $\mathrm{C}$ almost completely carbonized the

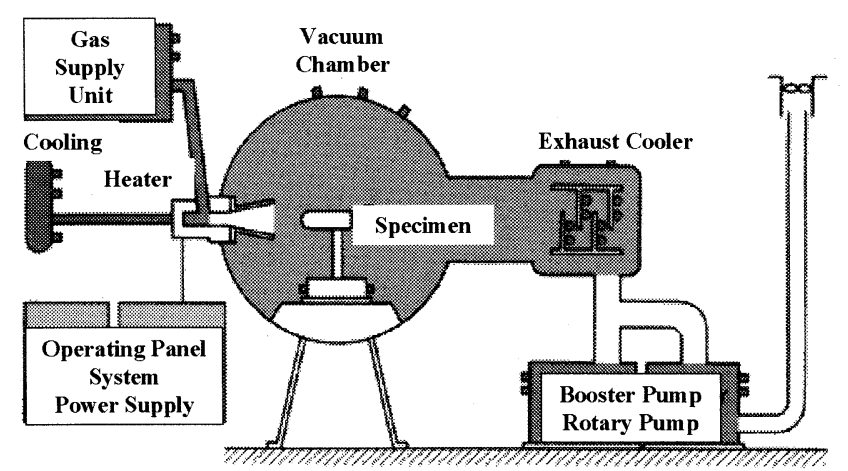

Fig.1 Arc-heating equipment at the Japan Ultra High Temperature Material Center (JUTEM).

Table 1 Test conditions for measuring surface mass loss rate in nitrogen gas atmosphere.

\begin{tabular}{|c|c|c|c|c|c|c|}
\hline \multirow{3}{*}{$\begin{array}{c}\text { Cpnditions } \\
\text { No. }\end{array}$} & \multicolumn{2}{|c|}{ Specimens } & \multicolumn{4}{|c|}{ Conditions } \\
\hline & \multirow[t]{2}{*}{ No. } & \multirow{2}{*}{$\begin{array}{c}\text { Evaluation } \\
\text { Materials }\end{array}$} & \multirow[t]{2}{*}{ Gas } & Duration & \begin{tabular}{|c|} 
Stagnation \\
Pressure
\end{tabular} & $\begin{array}{c}\text { Surface } \\
\text { Temperature }\end{array}$ \\
\hline & & & & $\mathrm{sec}$ & $\mathrm{Pa}$ & $\mathrm{K}$ \\
\hline \multirow{9}{*}{ A } & CF2 & \multirow{9}{*}{ Phenolic } & \multirow{9}{*}{$\begin{array}{c}\mathrm{N}_{2}: \mathrm{O}_{2}= \\
100: 0\end{array}$} & 300 & 309 & 1509 \\
\hline & CF3 & & & 300 & 314 & 1467 \\
\hline & CF4 & & & 300 & 316 & 1485 \\
\hline & CF5 & & & 300 & 306 & 1506 \\
\hline & \begin{tabular}{|l|} 
CF6 \\
\end{tabular} & & & 300 & 893 & 2005 \\
\hline & CF7 & & & 300 & 672 & 1857 \\
\hline & CF9 & & & 300 & 842 & 2183 \\
\hline & CF11 & & & 300 & 1010 & 2606 \\
\hline & CF12 & & & 300 & 842 & 2446 \\
\hline \multirow{3}{*}{ B } & CF3 & \multirow{3}{*}{$\begin{array}{l}\text { Phenolic } \\
\text { CFRP }\end{array}$} & \multirow{3}{*}{$\begin{array}{c}\mathrm{N}_{2}: \mathrm{O}_{2}= \\
100: 0\end{array}$} & 300 & 190 & \\
\hline & CF4 & & & 300 & 672 & \\
\hline & CF5 & & & 300 & 1010 & \\
\hline \multirow{3}{*}{$\mathrm{C}$} & CF5 & \multirow{3}{*}{$\begin{array}{l}\text { Phenolic } \\
\text { CFRP }\end{array}$} & \multirow{3}{*}{$\begin{array}{c}\mathrm{N}_{2}: \mathrm{O}_{2}= \\
100: 0\end{array}$} & 300 & 1010 & \\
\hline & \begin{tabular}{|l|} 
CF4 \\
\end{tabular} & & & 300 & 672 & \\
\hline & CF3 & & & 300 & 306 & \\
\hline \multirow{5}{*}{$\mathrm{D}$} & \begin{tabular}{|l|}
$\mathrm{CC} 1$ \\
\end{tabular} & \multirow{5}{*}{$\begin{array}{l}\text { Carbon- } \\
\text { Carbon }\end{array}$} & \multirow{5}{*}{$\begin{array}{c}\mathrm{N}_{2}: \mathrm{O}_{2}= \\
100: 0\end{array}$} & 300 & 728 & \\
\hline & $\mathrm{CC} 2$ & & & 300 & 314 & \\
\hline & $\mathrm{CC} 3$ & & & 300 & 316 & \\
\hline & \begin{tabular}{|l|}
$\mathrm{CC} 4$ \\
\end{tabular} & & & 300 & 893 & \\
\hline & CC5 & & & 300 & 842 & \\
\hline \multirow{4}{*}{ E } & CF13 & \multirow{4}{*}{$\begin{array}{l}\text { Phenolic } \\
\text { CFRP }\end{array}$} & \multirow{4}{*}{$\begin{array}{c}\mathrm{N}_{2}: \mathrm{O}_{2}= \\
75: 25\end{array}$} & 180 & 1010 & 2666 \\
\hline & CF14 & & & 180 & 842 & 2586 \\
\hline & CF15 & & & 238 & 1010 & 2606 \\
\hline & CF16 & & & 180 & 842 & 2446 \\
\hline
\end{tabular}

phenolic CFRP pieces and lowered their density to approximately $1180 \mathrm{~kg} / \mathrm{m}^{3}$.

We predicted that if carbonized phenol CFRP heated in the nitrogen atmosphere reacts with the thermal decomposition gas at the surface, it would undergo surface mass loss. In this case, the surface mass loss rate would be expected to be the largest in the condition A, becomes smaller in condition B, and becomes still smaller in condition $\mathrm{C}$.

The heating time durations for each test were $180 \mathrm{~s}$ to $300 \mathrm{~s}$, which were more than 6 times to 10 times that used in Sutton's 


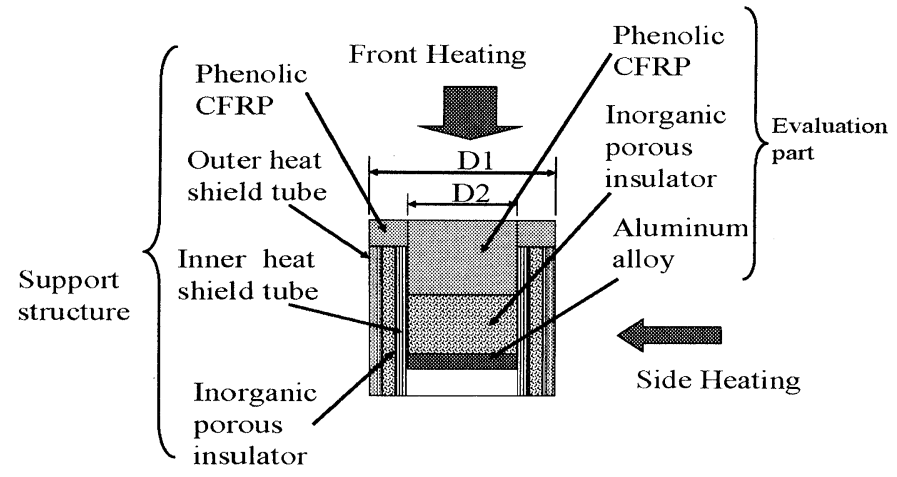

Fig.2 Schematic outline of specimen.

Table 2 Outline of specimen

\begin{tabular}{|c|c|c|c|}
\hline \multirow{4}{*}{$\begin{array}{l}\text { Support } \\
\text { structure }\end{array}$} & \multicolumn{2}{|r|}{ Diameter $\mathrm{D}_{1}(\mathrm{~m})$} & 0.04 \\
\hline & \multirow{2}{*}{\multicolumn{2}{|c|}{$\begin{array}{l}\text { Outside tube } \\
\text { Porosity heat insulating material }\end{array}$}} & GFRP \\
\hline & & & Alumina-silica fiber \\
\hline & \multicolumn{2}{|r|}{ Inner side tube } & GFRP \\
\hline \multirow{6}{*}{$\begin{array}{l}\text { Evaluation } \\
\text { part }\end{array}$} & \multicolumn{2}{|r|}{ Diameter $\mathrm{D}_{2}(\mathrm{~m})$} & 0.025 \\
\hline & \multirow{4}{*}{$\begin{array}{l}\text { Phenolic } \\
\text { CFRP }\end{array}$} & Density (virgin) $\left(\mathrm{kg} / \mathrm{m}^{3}\right)$ & 1470 \\
\hline & & Density (charred) $\left(\mathrm{kg} / \mathrm{m}^{3}\right)$ & 1180 \\
\hline & & $\begin{array}{l}\text { Thermal conductivity } \\
\text { (virgin) }(\mathrm{W} / \mathrm{m} / \mathrm{K})\end{array}$ & 0.67 \\
\hline & & $\begin{array}{l}\text { Specific heat of virgin } \\
(\mathrm{J} /(\mathrm{kg} \cdot \mathrm{K}))\end{array}$ & 950 \\
\hline & \multicolumn{2}{|c|}{ Porous insulator material } & Alumina-silica fiber \\
\hline
\end{tabular}

tests ${ }^{11)}$. The long heating duration enabled us to measure an extremely small surface mass loss rate.

The specimen used for the heating test is outlined in Fig.2 and details of structure are indicated in Table 2.

The specimen assembly is cylindrical, $0.040 \mathrm{~m}$ in diameter, and consists of an evaluation part and a support structure. A phenolic CFRP piece is placed at the front of the evaluation part and subjected directly to front heating. The support structure insulates the CFRP piece from side heating, and reinforces one-dimensional heat flow in the evaluation part. The support structure consists of an outer- and inner heat shield tube and an inorganic porous insulator with a low thermal diffusivity that is inserted between the two tubes. The outer and inner heat shield tubes are made of glass fiber-reinforced plastic (GFRP). The test piece to be evaluated is inserted into the inner tube.

\section{Results}

\subsection{Boundary between the rate-controlled oxidation region and the diffusion-controlled oxidation region}

Fig.3 shows the relation between the logarithm of the surface mass loss rate $\ln (\dot{m})$ and the inverse surface temperature $1 / T w$ measured in the condition $\mathrm{A}$.

Surface mass loss rate $\dot{m}$ is estimated by $\dot{L} \rho_{c h} . \dot{L}$ is obtained by dividing the surface recession difference of the specimen before

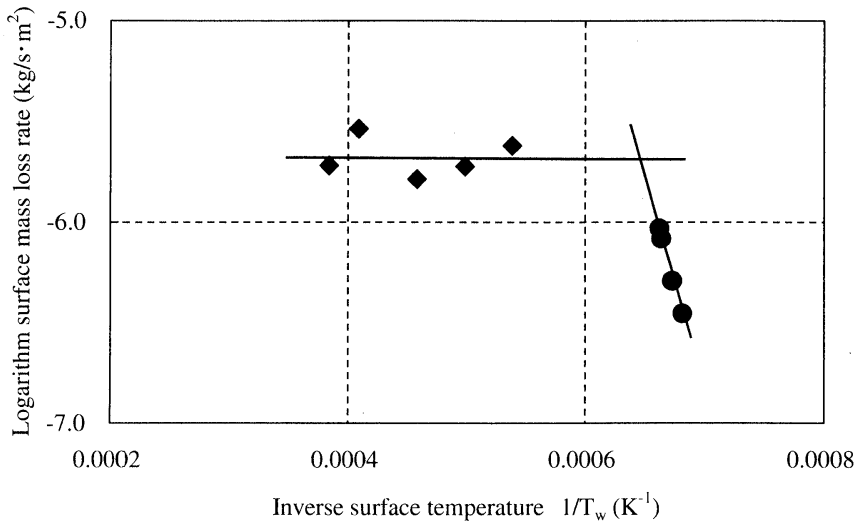

Fig.3 Relation between the logarithm of the surface mass loss rate and the inverse surface temperature of the carbonized phenolic CFRP heated in nitrogen gas atmosphere. (Data of the surface mass loss rate in approximately $1500 \mathrm{~K}$ or less (condition A), $\diamond$ : Data of the surface mass loss rate in approximately $1500 \mathrm{~K}$ or more (condition A).)

and after heating by the heating duration. $\rho_{c h}$ is the density of completely carbonized phenolic CFRP. As predicted, Fig.3 reveals that phenolic CFRP experiences surface mass loss even in the nitrogen atmosphere. As the surface temperature increases, the surface mass loss rate increases sharply until the temperature reaches $1600 \mathrm{~K}$ (or $6.4 \times 10^{-4} 1 / \mathrm{K}$ ) and then the increase becomes gradual at higher temperatures. In the nitrogen gas atmosphere, therefore, the relation between the surface mass loss of the carbonized phenolic CFRP and the surface temperature can be divided into two distinct regions. The boundary temperature between the two regions is approximately $1600 \mathrm{~K}$.

The above result demonstrates that even when no oxygen is present in the free stream, the oxygen present in the gas resulting due to the thermal decomposition of phenolic resin causes the surface mass loss of carbonized phenolic CFRP.

\subsection{Thermochemical characteristics of the rate-controlled oxidation region}

The surface mass loss rate of the graphite in the rate-controlled oxidation region $\dot{m}_{R}$ can be calculated by Eq. (1) ${ }^{7)}$ :

$$
\dot{m}_{R}=k_{0} \sqrt{\zeta_{o} P_{e}} e^{-E / R T_{n}}
$$

Where $P_{e}$ is the stagnation pressure $(\mathrm{Pa}), k_{0}$ is the collision frequency factor $\left(\mathrm{kg} / \mathrm{s} \cdot \mathrm{m}^{2} \cdot \mathrm{Pa}^{1 / 2}\right), \zeta_{0}$ is the mole fraction of oxygen $(-), E$ is the activation energy $(\mathrm{J} / \mathrm{mol}), R$ is the universal gas constant $(8.314 \mathrm{~J} / \mathrm{mol} \cdot \mathrm{K})$, and $T_{W}$ is the surface temperature $(\mathrm{K})$. The results of the heating tests are summarized in Table 3 .

A micrograph of the virgin phenolic CFRP before heating is shown in Fig.4, and that of the carbonized phenolic CFRP (No.CF9) after heating is shown in Fig.5.

Fig.4 shows a phenolic resin between fibers. On the other hand, Fig.5 reveals few resin particles left between fibers and small holes 
Table 3 Surface mass loss rate of phenolic CFRP in inert gas atmosphere

\begin{tabular}{|c|c|c|c|c|c|c|c|c|}
\hline \multirow{4}{*}{$\begin{array}{c}\text { Conditions } \\
\text { No. }\end{array}$} & \multicolumn{2}{|c|}{ Specimens } & \multirow{4}{*}{ Gas } & \multicolumn{4}{|c|}{ Test Results } & \multirow{4}{*}{$\begin{array}{c}\text { Notes } \\
\text { (for Fig.3) }\end{array}$} \\
\hline & \multirow{3}{*}{ No. } & \multirow{3}{*}{$\begin{array}{c}\text { Evaluation } \\
\text { Materials }\end{array}$} & & \multicolumn{3}{|c|}{ Density } & \multirow[b]{2}{*}{$\begin{array}{c}\text { Surface Mass Loss } \\
\text { Rate }\end{array}$} & \\
\hline & & & & $\begin{array}{l}\text { Before } \\
\text { Heating }\end{array}$ & $\begin{array}{l}\text { After } \\
\text { Heating }\end{array}$ & Average & & \\
\hline & & & & $\mathrm{kg} / \mathrm{m}^{3}$ & $\mathrm{~kg} / \mathrm{m}^{3}$ & $\mathrm{~kg} / \mathrm{m}^{3}$ & $\mathrm{~kg} / \mathrm{s} \cdot \mathrm{m}^{2}$ & \\
\hline \multirow{9}{*}{ A } & $\mathrm{CF} 2$ & \multirow{9}{*}{$\begin{array}{l}\text { Phenolic } \\
\text { CFRP }\end{array}$} & \multirow{9}{*}{$\begin{array}{c}\mathrm{N}_{2}: \mathrm{O}_{2}= \\
100: 0\end{array}$} & 1483 & 1269 & 1376 & $2.40 \mathrm{E}-03$ & 0 \\
\hline & CF3 & & & 1475 & 1310 & 1393 & $1.57 \mathrm{E}-03$ & 0 \\
\hline & $\mathrm{CF} 4$ & & & 1467 & 1289 & 1378 & $1.85 \mathrm{E}-03$ & 0 \\
\hline & CF5 & & & 1463 & 1298 & 1381 & $2.28 \mathrm{E}-03$ & 0 \\
\hline & CF6 & & & 1469 & 1238 & 1354 & $3.26 \mathrm{E}-03$ & $\bullet$ \\
\hline & CF7 & & & 1464 & 1244 & 1354 & $3.62 \mathrm{E}-03$ & $\bullet$ \\
\hline & CF9 & & & 1468 & 1200 & 1334 & $3.07 \mathrm{E}-03$ & $\bullet$ \\
\hline & CF11 & & & 1479 & 1212 & 1346 & $3.28 \mathrm{E}-03$ & 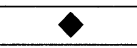 \\
\hline & CF12 & & & 1504 & 1260 & 1382 & 3.93E-03 & 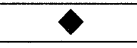 \\
\hline \multirow{3}{*}{ B } & CF3 & \multirow{3}{*}{$\begin{array}{l}\text { Phenolic } \\
\text { CFRP }\end{array}$} & \multirow{3}{*}{$\begin{array}{c}\mathrm{N}_{2}: \mathrm{O}_{2}= \\
100: 0\end{array}$} & 1310 & 1294 & 1302 & $1.18 \mathrm{E}-04$ & \\
\hline & CF4 & & & 1289 & 1228 & 1258 & $1.77 \mathrm{E}-03$ & \\
\hline & CF5 & & & 1298 & 1235 & 1266 & $2.44 \mathrm{E}-03$ & \\
\hline \multirow{3}{*}{ C } & CF5 & \multirow{3}{*}{$\begin{array}{l}\text { Phenolic } \\
\text { CFRP }\end{array}$} & \multirow{3}{*}{$\begin{array}{c}\mathrm{N}_{2}: \mathrm{O}_{2}= \\
100: 0\end{array}$} & 1235 & 1203 & 1219 & $1.22 \mathrm{E}-03$ & \\
\hline & CF4 & & & 1228 & 1223 & 1225 & $5.90 \mathrm{E}-04$ & \\
\hline & CF3 & & & 1294 & 1247 & 1270 & $1.77 \mathrm{E}-03$ & \\
\hline \multirow{5}{*}{ D } & $\mathrm{CC} 1$ & \multirow{5}{*}{$\begin{array}{l}\text { Carbon- } \\
\text { Carbon }\end{array}$} & \multirow{5}{*}{$\begin{array}{c}\mathrm{N}_{2}: \mathrm{O}_{2}= \\
100: 0\end{array}$} & 1621 & 1615 & 1618 & $6.49 \mathrm{E}-04$ & \\
\hline & $\mathrm{CC} 2$ & & & 1626 & 1624 & 1625 & $1.08 \mathrm{E}-04$ & \\
\hline & $\mathrm{CC} 3$ & & & 1617 & 1615 & 1616 & $5.39 \mathrm{E}-05$ & \\
\hline & $\mathrm{CC} 4$ & & & 1639 & 1625 & 1632 & $5.46 \mathrm{E}-05$ & \\
\hline & CC5 & & & 1629 & 1600 & 1615 & $1.09 \mathrm{E}-04$ & \\
\hline \multirow{4}{*}{ E } & CF13 & \multirow{4}{*}{$\begin{array}{l}\text { Phenolic } \\
\text { CFRP }\end{array}$} & \multirow{4}{*}{$\begin{array}{c}\mathrm{N}_{2}: \mathrm{O}_{2}= \\
75: 25\end{array}$} & 1483 & 1235 & 1359 & $1.17 \mathrm{E}-02$ & \\
\hline & CF14 & & & 1464 & 1235 & 1350 & $1.14 \mathrm{E}-02$ & \\
\hline & CF15 & & & 1475 & 1232 & 1353 & $1.20 \mathrm{E}-02$ & \\
\hline & CF16 & & & 1458 & 1227 & 1343 & $1.01 \mathrm{E}-02$ & \\
\hline
\end{tabular}

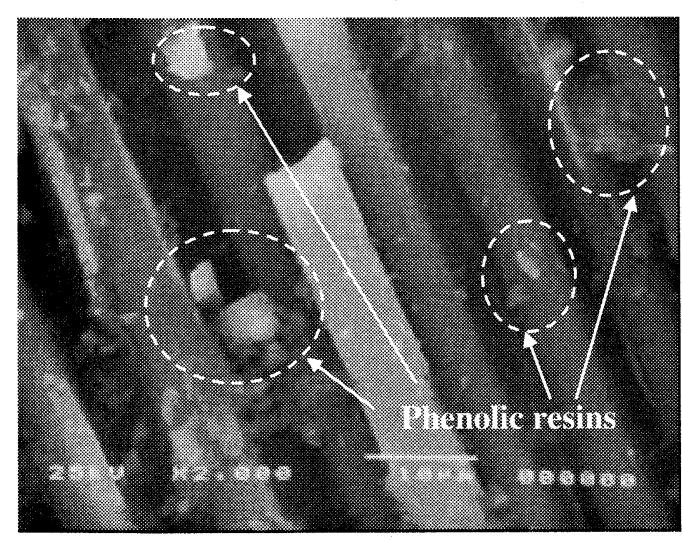

Fig.4 Virgin phenolic CFRP before heating.

created in the fibers.

By taking the logarithm of both sides of Eq. (1), we obtain Eq. (2):

$$
\ln \left(\dot{m}_{R}\right)=-\frac{E}{R T_{w}}+\ln \left(k_{0} \sqrt{\zeta_{o} P_{e}}\right)
$$

The steep straight line on the right-hand side of Fig.3 is in the rate-controlled oxidation region, and it represents the relation between the inverse heating temperature and the logarithm of the surface mass loss rate of the carbonized phenolic CFRP subjected

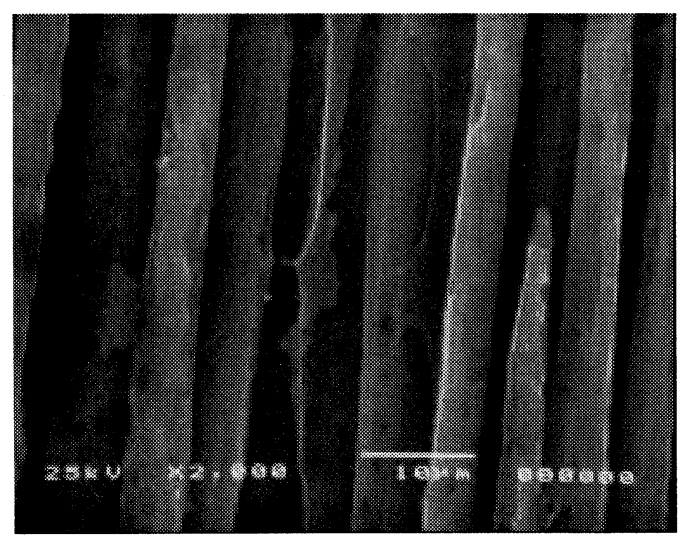

Fig.5 Carbonized phenolic CFRP after heating (Specimen No.CF9).

to the condition A. As shown in the figure, the inclination of the line, which corresponds to $\mathrm{E} / \mathrm{R}$ in $\mathrm{Eq}$. (2), was $2.2 \times 10^{4} \mathrm{~K}$, from which the activation-energy $\mathrm{E}$ was estimated to be $182.4 \mathrm{~kJ} / \mathrm{mol}$. In addition, the second term on the right-hand side of Eq. (2) was found to be 8.50 . Solving $8.50=\ln \left(k_{0} \sqrt{\zeta_{o} P_{e}}\right)$ with respect to the collision-frequency factor $k_{0}$, we obtain $k_{0}=4914.7 / \sqrt{\zeta_{o} P_{e}}$.

\subsection{Thermochemical characteristics of the diffusion -controlled oxidation region}

In the diffusion-controlled oxidation region that lies in a surface 


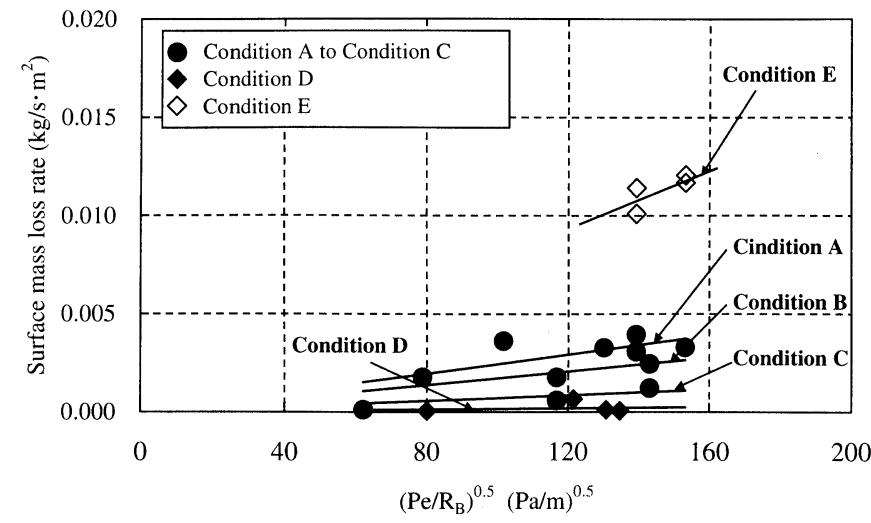

Fig.6 Relation between surface mass loss rate and $\left(P_{e} / R_{B}\right)^{0.5}$ of carbonized phenolic CFRP in nitrogen atmosphere.

temperature range above $1600 \mathrm{~K}$, the surface mass loss rate $\dot{m}_{D}$ can be expressed by Eq. (3) ${ }^{7)}$ :

$$
\dot{m}_{D}=C_{0} \sqrt{P_{e} / R_{B}}
$$

Where $C_{0}$ is the diffusion-controlled oxidation constant $(\mathrm{kg} / \mathrm{s}$. $\left.\mathrm{m}^{3 / 2} \cdot \mathrm{Pa}^{1 / 2}\right)$ and $R_{B}$ is the correction radius of the surface of the specimen $(\mathrm{m})$. When the front surface of the specimen is flat, the correction radius $R_{B}$ is 2.46 times the actual radius of the specimen ${ }^{7)}$. Since the front surface of the specimens used for this study is flat and diameter is $0.040 \mathrm{~m}$, the correction radius $R_{B}$ becomes $0.049 \mathrm{~m}$.

Fig.6 shows the relation between the surface mass loss rate $\dot{m}_{D}$ and $\sqrt{P_{e} / R_{B}}$ in the condition A. It reveals that the larger the mean density $\rho_{a v}$, the larger the surface mass loss rate. In the condition $\mathrm{C}$, the densities of specimens are nearly equal to that of completely carbonized phenolic CFRP. Based on these results, it was ascertained that carbonized phenolic CFRP in nitrogen gas atmosphere undergoes surface mass loss due to the oxygen present in the decomposition gas. The values of $C_{0}$ for different test conditions are given as the slopes of the straight lines presented in Fig.6.

By substituting these values in Eq. (3), the surface mass loss rates of the carbonized phenolic CFRP in the conditions $\mathrm{A}, \mathrm{B}$, and $\mathrm{C}$ are expressed as the functions of $P_{e} / R_{B}$ by Eqs. (4) through (6). The experimental values of the conditions A through $C$ plotted to Fig.6 are in the diffusion-controlled oxidization region :

$$
\begin{aligned}
& \dot{m}_{D}=2.0 \times 10^{-5}\left(P_{e} / R_{B}\right)^{0.5} \text { for the condition A } \\
& \dot{m}_{D}=1.7 \times 10^{-5}\left(P_{e} / R_{B}\right)^{0.5} \text { for the condition B } \\
& \dot{m}_{D}=0.61 \times 10^{-5}\left(P_{e} / R_{B}\right)^{0.5} \text { for the condition } \mathrm{C}
\end{aligned}
$$

On the other hand, $C_{0}$ can be treated as a variable and be calculated from the values of surface mass loss rate $\dot{m}_{D}$, stagnation pressure $P_{e}$, and correction radius $R_{B}$ measured under different conditions. The Metzger's theory cannot express the pyrolysis reaction of the

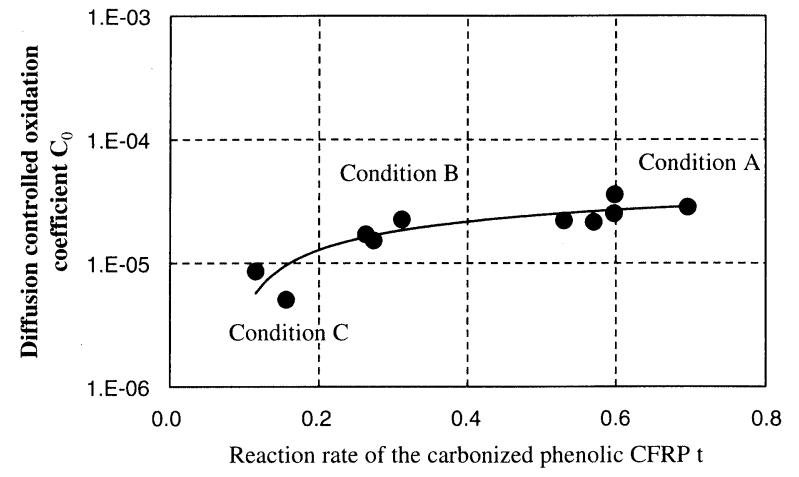

Fig.7 Relation between diffusion-controlled oxidation constant $C_{0}$ and reaction rate $\tau$ of carbonized phenolic CFRP in nitrogen atmosphere.

phenolic CFRP. In this study, it was assumed that $C_{0}$ could express as a function of the reaction rate $\tau^{9)}$. In Fig.7, the calculated values of $C_{0}$ for the conditions $\mathrm{A}, \mathrm{B}$, and $\mathrm{C}$ are plotted against the reaction rate $\tau$ as defined in Eq. (8). As indicated in the figure, the diffusioncontrolled oxidation constant $C_{0}$ of the carbonized phenol CFRP is then expressed as a function of the reaction rate $\tau$ by Eq. (7) :

$$
\begin{aligned}
& C_{0}=1.3 \times 10^{-5} \ln (\tau)+3.3 \times 10^{-5} . \\
& \tau=\frac{\rho_{a v}-\rho_{c h}}{\rho_{v}-\rho_{c h}} \ldots \ldots \ldots \ldots \ldots \ldots \ldots \ldots \ldots \ldots \ldots \ldots \ldots \ldots \ldots \ldots
\end{aligned}
$$

As previously mentioned, the density of the virgin material, $\rho_{v}$, was approximately $1470 \mathrm{~kg} / \mathrm{m}^{3}$, and the density after complete carbonization, $\rho_{c h}$, was approximately $1180 \mathrm{~kg} / \mathrm{m}^{3} . \rho_{a v}$ was the average densities in Table 3.

\section{Discussion}

\subsection{Nitriding reaction of the carbon-carbon composite}

In order to investigate the nitriding of carbon materials that do not contain resin, a carbon-carbon composite material was subjected to intense heating in the nitrogen atmosphere. It was expected that the carbon-carbon composite material would not experience such a surface mass loss as would be caused by the oxygen in thermal decomposition gas.

The test condition was the condition $\mathrm{D}$ as shown in Table $\mathbf{1}$. The carbon-carbon composite specimen was $0.040 \mathrm{~m}$ in diameter, and its density was approximately $1620 \mathrm{~kg} / \mathrm{m}^{3}$. The specimen assembly was the same as that illustrated in Fig.1 with the exception that the material to be evaluated was a carbon-carbon composite and not a phenolic CFRP.

The surface mass loss rates of the carbon-carbon composite tested in the condition D are shown in Fig.6. The experimental values of the condition D plotted to Fig.6 are in the diffusion-controlled oxidization region. The figure demonstrates that the surface mass loss rate of the carbon-carbon composite heated in the nitrogen 
atmosphere is similar to that of the phenolic CFRP heated in the condition $\mathrm{C}$, and this mass loss rate for the condition $\mathrm{D}$ can be expressed by Eq. (9) as follows :

$$
\dot{m}_{D}=0.15 \times 10^{-6}\left(P_{e} / R_{B}\right)^{0.5}
$$

This surface mass loss caused by the nitriding of carbon must be subtracted from the mass loss caused by oxidation in order to obtain the correct oxidation surface mass loss.

\subsection{Oxidation of the phenolic CFRP in the air}

In order to understand the thermochemical reaction of the carbonized phenolic CFRP in nitrogen atmosphere, it is important to compare the oxidation surface mass loss rate of the material in nitrogen atmosphere with that in air. Thus, a test was conducted to heat the carbonized phenolic CFRP in an atmosphere that somewhat simulated the air (the condition $\mathrm{E}$ in Table 1). The specimen configuration was the same as that illustrated in Fig.1. The material to be evaluated was a virgin phenolic CFRP.

The surface mass loss rate of the carbonized phenolic CFRP heated in the condition E is shown in Fig.6 and is expressed as a function of $P_{e} / P_{B}$ for the condition E by Eq. (10). The experimental values of the condition E plotted to Fig. 6 are in the diffusioncontrolled oxidization region :

$$
\dot{m}_{D}=7.7 \times 10^{-5}\left(P_{e} / R_{B}\right)^{0.5}
$$

On comparing Eqs. (4) and (10) indicates that percentage ratio of the surface mass loss rate of the phenolic CFRP heated at temperatures above $1600 \mathrm{~K}$ in the condition $\mathrm{A}$ to that of the same material heated in the condition $\mathrm{E}$ is approximately $26 \%$. This suggests that the amount of oxygen in the decomposition gas is approximately $26 \%$ of that in air. A similar comparison of the surface mass losses in the conditions $\mathrm{B}$ and $\mathrm{C}$ with that in the condition $\mathrm{E}$ yields percentage ratios of $22 \%$ and $8 \%$, respectively.

According to Okuyama et al. ${ }^{14)}$, the collision-frequency factor $k_{0}$ of the carbonized phenolic CFRP in the high enthalpy airflow is $0.72 \mathrm{~kg} / \mathrm{s} \cdot \mathrm{m}^{2} \cdot \mathrm{Pa}^{1 / 2}$. As described in Section $3.2, k_{0}$ in the inert gas atmosphere of the condition A was estimated to be $4914.7 / \sqrt{\zeta_{o} P_{e}}$. On the other hand, $\zeta_{o}$ in the present study is expressed as a function of the reaction rate $\tau$ by Eq. (11). Because, the Metzger's theory cannot estimate the surface mass loss rate by the oxidization based on the oxygen in the pyrolysis gas of the phenolic CFRP diffused into the nitrogen atmosphere :

$$
\zeta_{o} \equiv \tau \chi
$$

Therefore, we obtain

$$
\begin{array}{r}
k_{0}=0.72=4914.7 / \sqrt{\tau \chi P_{e}} \\
\therefore \chi=46.6 \times 10^{6} /\left(\tau P_{e}\right)
\end{array}
$$

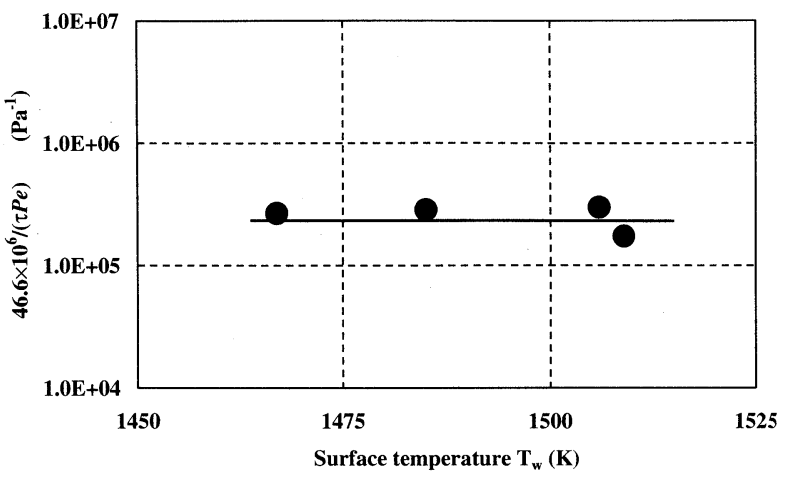

Fig.8 Relation between $46.6 \times 10^{6} /\left(\tau P_{e}\right)(=\chi)$ and the surface temperatures of the carbonized phenolic CFRP in nitrogen gas atmosphere.

The right-hand side of Eq. (12) was first calculated from the values of $\tau$ (Eq. (8)) and $P_{e}$ that were measured at temperatures below $1600 \mathrm{~K}$ in the condition $\mathrm{A}$ and was then plotted against temperature in Fig.8.

This leads to $\chi=0.24 \times 10^{6}$ for the phenolic CFRP. Finally, the collision-frequency factor $k_{0}$ of the carbonized phenolic CFRP in the high enthalpy flow of nitrogen gas is expressed as the function of $\tau$ and $P_{e}$ by $k_{0}=4914.7 / \sqrt{0.24 \times 10^{6} \tau P_{e}}=10.0 / \sqrt{\tau P_{e}}$.

In the section $3.2, k_{0}$ was expressed by $4914.7 / \sqrt{\zeta_{o} P_{e}}$. This $k_{0}$ cannot predict surface mass loss rate by the oxygen contained in pyrolysis gas. By having clarified the relation of $k_{0}=10.0 / \sqrt{\tau P_{e}}$, prediction of the surface mass loss rate by the oxygen contained in pyrolysis gas was attained.

\section{Conclusion}

Surface mass loss rate of carbon materials such as graphite and the phenolic CFRP etc. has been predicted using the Metzger's theory. This Metzger's theory cannot estimate the surface mass loss rate by the oxidization based on the oxygen in the pyrolysis gas diffused into the nitrogen atmosphere. When the phenolic CFRP is heated, the phenolic resin is pyrolyzed and the gas containing oxygen generates it. Therefore, prediction of the surface mass loss rate of the phenolic CFRP in the nitrogen gas atmosphere was difficult.

The present study clarified the oxidation reaction of the phenolic CFRP in the nitrogen gas atmosphere. Concretely, the oxidization region of the phenolic CFRP can be classified into two, the ratecontrolled region and the diffusion-controlled region. In these two oxidization regions, the thermochemical characteristics that the surface mass loss rate of the phenolic CFRP could be found were clarified. These thermochemical characteristics of the phenolic CFRP in these two regions are shown below :

1) In nitrogen atmosphere, the relation between the surface mass losses of the carbonized phenolic CFRP heated to a temperature below $3000 \mathrm{~K}$ and the surface temperature can be divided into two distinct regions - the rate-controlled region and the diffusion- 
controlled region. The boundary temperature between the two is approximately $1600 \mathrm{~K}$.

2) In the rate-controlled oxidation region, the inclination of the line that represents the logarithm of surface mass loss rate as a function of inverse temperature, which corresponds to $E / R$, was $2.2 \times 10^{4} \mathrm{~K}$, from which the activation-energy $E$ was estimated to be $182.4 \mathrm{~kJ} / \mathrm{mol}$. The collision-frequency factor $k_{0}$ was given by $k_{0}=10.0 / \sqrt{\tau P_{e}}$.

3) The surface mass loss rates of the carbonized phenolic CFRP are shown in the following equations $: \dot{m}_{D}=2.0 \times 10^{-5}\left(P_{c} / R_{B}\right) 0.5$ for the condition $\mathrm{A}, \dot{m}_{D}=1.7 \times 10^{-5}\left(P_{e} / R_{B}\right) 0.5$ for the condition $\mathrm{B}$, and $\dot{m}_{D}=0.61 \times 10^{-5}\left(P_{e} / R_{B}\right) 0.5$ for the condition $\mathrm{C}$.

4) In nitrogen atmosphere, the diffusion-controlled oxidation constant $C_{0}$ of the carbonized phenol CFRP can be expressed as a function of $\tau$ by $C_{0}=1.3 \times 10^{-5} \ln (\tau)+3.3 \times 10^{-5}$.

5) The surface mass loss rate of a carbon-carbon composite, which does not contain resin, is expressed by $\dot{m}_{D}=0.15 \times 10^{-5}\left(P_{e} / R_{B}\right) 0.5$. This surface mass loss caused by the nitriding of carbon must be subtracted from the surface mass loss caused by oxidation in order to obtain the correct oxidation surface mass loss.

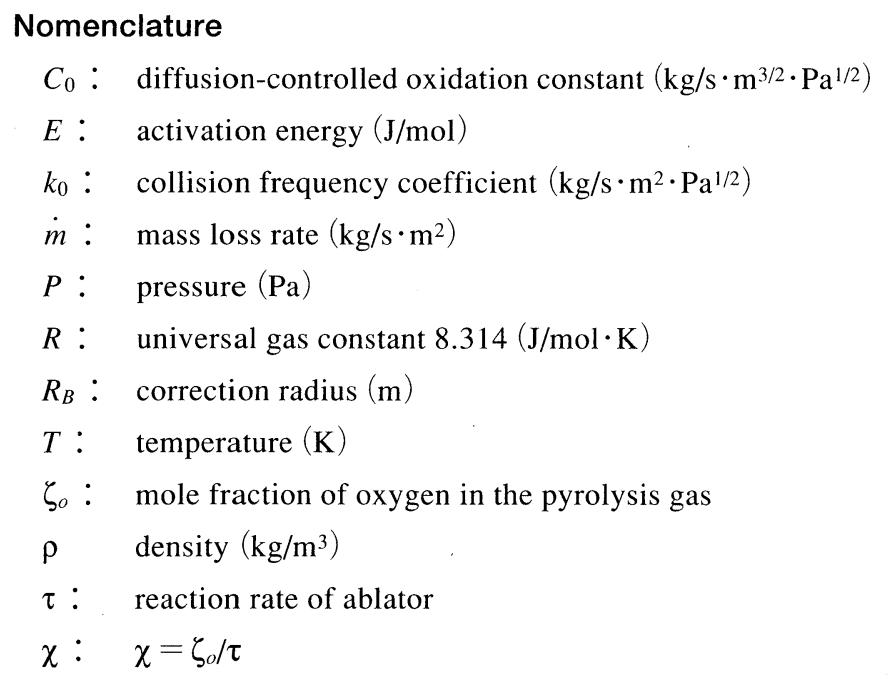

\section{Subscripts}

$\begin{array}{ll}a b: & \text { ablation } \\ a v: & \text { average } \\ c h: & \text { char } \\ D: & \text { diffusion-controlled oxidation region } \\ e: & \text { stagnation point }\end{array}$

$$
\begin{array}{ll}
R: & \text { rate-controlled oxidation region } \\
v: & \text { virgin } \\
w: & \text { surface of specimen }
\end{array}
$$

\section{Acknowledgement}

The authors would like to thank the Japan Ultra high Temperature Material center (JUTEM) for their technical support.

\section{References}

1) J. N. Moss and A. L. Simmonds, Galileo probe Forebody Flowfield Predictions, Entry Vehicle Heating and Thermal Protection Systems: Space Shuttle, Solar Starprobe, Progress in. Astronautics and Aeronautics, Vol.85 (P. E. Bauer and H. E. Collicott, eds.) (1983) pp.419-445, AIAA, New York.

2) W. D. Henline et al., Thermal Protection System Development and Application to Planetary Entry Vehicles, $1^{\text {st }}$ ESA/ESTEC workshop on thermal protection system, (1993).

3) Y. K. Chen et al., Ablation and Thermal Response Program for Spacecraft Heat Shield Analysis, J. of Space-craft and Rockets, 36 [2] (1999), 475-483.

4) T. Yamada, K. Hiraki, N. Ishii and Y. Inatani, Thermal Protection System of MUSES-C Re-Entry Capsule, $21^{\text {st }}$ int. symposium on space technology and science, Sonic City, Omiya, Japan, (1998).

5) Y. Kanno, R. Sakata, S. Ogiso, S. Bandoh, M. Sugawara and K. Hama, USERS/REM Heat Shield Design Concept and Strength Analysis, ISTS 2000-c-28, Morioka, Japan, 5.28-6.4 (2000).

6) K. Okuyama, S. Kato, R. Sakata, M. Uto, K. Hama and Y. Inatani, The Arc-Heated Test Results for USERS/REM Heat Shield System Development, ISTS 2000-q-25, Morioka, Japan 5.28-6.4 (2000).

7) J. W. Metzger, M. J. Enge and N. S. Diaconis, Oxidation and Sublimation of Graphite, AIAA. J., 5 [3] (1967).

8) C. Park, Effects of Atomic Oxygen on Graphite Ablation, AIAA J., 14 [11] (1976)

9) R. L. Potts, Application of Integral Methods to Ablation Charring Erosion, A Review, J. Space-craft, 32 [2], (1995), 200-209.

10) R. L. Potts, Hybrid Integral/Quasi-Steady Solution of Charring Ablation, AIAA/ASME $5^{\text {th }}$ joint thermo physics and heat transfer conference, Seattle WA, 6.18-6.20, (1990).

11) K. Sutton, An Experimental Study of a Carbon-Phenolic Ablation Material, NASA TN D-5930, (1970).

12) K. Hanawa, M. Ishii and M. Matsumoto, Development of Erosion Testing Machine as High Enthalpy Arc-Heated Wind Tunnel, The symposium on ultra-high temperature materials '92 in Tajimi, (1992) Tajimi [in Japanese].

13) http://www.c-5.ne.jp/ jutem-co/erosiontest.htm

14) K. Okuyama, S. Kato, T. Yamada and M. Zako, Oxidation Characteristics of the Carbonized CFRP under The Air Environments, TANSO 2004 [No.213]128-133 [in Japanese]. 